\title{
Scenes from an unlikely marriage: Building a corporate culture in biotechnology
}

\section{The first step to creating a corporate identity is identifying the obstacles.}

\author{
Christopher S. Henney
}

Biotechnology companies in their early stages are very fragile organisms. Perhaps one of the least addressed issues in ensuring their maturity and growth is the nurturing of their internal identity. This process of creating a system that smoothes the inevitable internal friction in the workplace is generally known as creating a "corporate culture."

While all successful companies have one, defining it is more difficult. If you think about the differences between the cultures of Microsoft and IBM, you instantly understand that success in this regard can come in very different packages. I believe that all truly great companies grow from distinctive cultures that reflect leadership styles. Nowhere in the development of a company are the skills of the CEO more necessary nor more apparent.

I have not been able to discern a clear pattern of what the good companies do that is special in this regard, but it has been rather easy for me to define what they do not dowhich may be just as important. Good companies, through good CEOs, try to establish a frictionless society. They acknowledge that there are differences and try to avoid the major sources of irritation. I offer, anecdotally, my own view of what has worked, and what hasn't, in my career in biotechnology.

\section{Scientist as startup CEO}

By business school criteria, biotechnology businesses look like nothing the business community has ever seen. This is not only because they consume enormous amounts of cash and take an inordinately-in business terms, unacceptably-long time to become profitable. It is also because they try to marry the very different cultures of business and biological science, which have traditionally demonstrated little interest in each other.

This cultural split is deeply rooted in the

Christopher S. Henney is CEO of Dendreon Corp., 91 North Bernardo Avenue, Mountain View, CA 94043 (chenney@dendreon.com).
The business world is structured in a way everyone understands and all scientists hate: "You work for me, I work for my boss, and everyone works for the CEO."

training of scientists. The unwritten "laws" we scientists learn as undergraduates, and in graduate school, govern what makes us tick. These tenets are so ingrained in our scientific upbringing that they are second nature. Many of the values that businesses see as important in the workplace, scientists are taught to regard as trivial.

Given this discord, a bioentrepreneur has to create a strategy that will mend this rift while building real value in the organization. It is not cynical to conclude that, in most cases, for the first several years of its existence the initial value of the organization is being built, not in its product portfolio, but in its research organization.

I believe that this is the strongest argument for the case that the CEO, at least of an early-stage biotechnology company, should be a scientist. Furthermore, I think the first statement that should be made in establishing a corporate culture is the recognition that these are science-driven organizations and that the most important employees are the scientists. Far too often this goes unsaid, but it has been a very clear message in the successes of the Amgens, the Genentechs, and the Chirons of the industry.

\section{Business CEO and science}

Despite my championing of scientist CEOs, some venture capitalists and Wall Street favor business CEOs at the helm. It seems inevitable, then, that most biotechnology businesses will, at some stage, have a nonscientist as CEO.

What are the major issues that face them? The first is to accept the simple fact that no CEO becomes a scientist simply by being hired to run a biotechnology company. This is more difficult in practice than it seems. Far too many CEOs adopt some version of the following simplistic argument: "Science is so difficult I won't bother to try to understand it. I don't need to because businesspeople know that scientists simply want to pursue their own esoteric needs. My dentist knows more about products than my head of R\&D. Therefore, in collaboration with my friends and my bankers, I'll decide what science we'll pursue."

Such CEOs invariably address the head of R\&D with, "Why aren't we doing EPO?" or "Where is my EPO?" or "Why does R\&D cost so much?" Nothing increases the business/science divide more than questions such as these. Similarly, a CEO who, on being told some bad news by his head of R\&D and, not understanding the nature of the problem, answers, "fire them" is being decisive at the expense of ever being told the truth again. Obviously, this is not the route to building a culture of open communication or of successfully marrying business and science.

\section{Who works for whom}

The business world is structured in a way everyone understands and all scientists hate: "You work for me, I work for my boss, and everyone works for the CEO." The world of academic science is, at least superficially, much more egalitarian. No one in academia likes to think that he has a boss, merely that he has someone who is administratively responsible for them. The merging of these two cultural perspectives has been uniformly difficult in biotechnology companies.

The usual compromise is the construction of a organizational chart that silently announces who works for whom in a culture where the words can't be spoken. These charts are often called "Where's Waldo?" by cynics, because they are only used by the viewer to locate his or her position in the company. In my opinion, "He works for me" is an objectionable phrase, and organizational charts should be used only to exchange information with other organizations. 


\section{Wherever you want to go in biotechnology, we can help you get there faster...}

\section{If you are a scientist doing biotechnology research...or Presumably, these employees are under the impression that they were hired as part of the company's quest for the "truth."} a businessperson looking to bring biotechnology research into commercial applications...you may want to consider becoming a Nature Biotechnology subscriber. Think of us as you where you want to go in biotechnology research, application, and commercialization.

MANAGEMENT

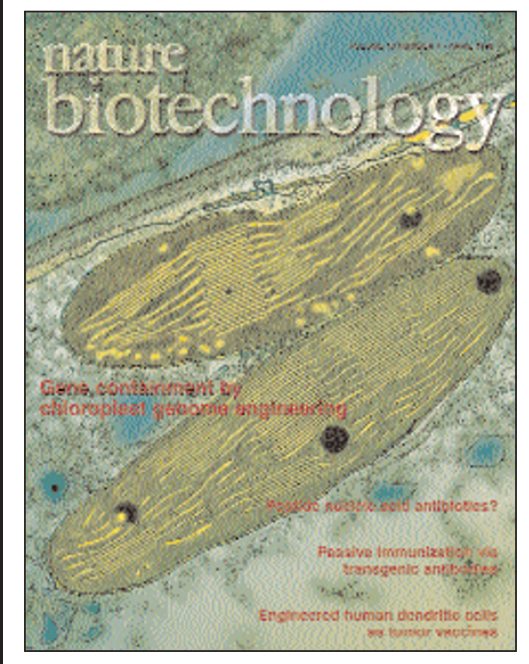

For more information or to order your personal subscription please contact us.

In North and South America Telephone 8005240384 (outside the US) 6153773322 Fax 6153770525 e-mail: subscriptions@natureny.com

In Australia

Telephone 61 (03) 96459444

Fax $61(03) 96457222$

In Japan

Telephone $81(0) 332678751$

Fax 81 (0) 332678746

e-mail: subscriptions@naturejpn.com

In Europe and Rest of World

Telephone $44(0) 1718434862$

Fax 44 (0) 1718434998

e-mail: subscriptions@nature.com

\section{The "P" word}

I know of no biotechnology company where the head of R\&D has not, at sometime or another, been faced with a staff member who was uncomfortable with the concept that he or she was working on a product. This word is so distasteful to some that is is referred to as the "P" word, not to be mentioned in full.

I have always assumed that the reason why some biotechnology companies style themselves as institutes rather than corporations was related to an attempt to hide the fact that products were being worked on. In order to prevent any delusions at the lab bench, I believe strongly that the corporate culture should spell out clearly that "product" is not a dirty word and that it is the primary reason for going to the corporate laboratory.

\section{The scientific advisory board}

A group of esteemed scientific counselors, experienced in the area of the company's scientific themes, is generally viewed to be of enormous value to a young company. My experience, and the notes I have shared with others, are surprisingly at odds with this conclusion. Why should this be so? For one thing, a strong scientific advisory board (SAB), by making corporate decisions, can stifle the company's ability to hire senior scientific talent of its own.

If the $\mathrm{SAB}$ reports directly to the $\mathrm{CEO}$, top talent may view these board members as directly competing for their roles. On the other hand, a very weak $S A B$, which meets too infrequently or is disinterested, has little or no influence. The latter case seems to be the trend. More and more CEOs treat the SAB as "window-dressing" for corporate fund-raising. When the board accepts this role, neither they nor the company are well served.

Most disturbingly, many $\mathrm{R} \& \mathrm{D}$ directors believe that the $\mathrm{SAB}$ is filled with the company's competitors and serves as a sieve for corporate research findings, without any compensating inflow of the latest information from the SAB laboratories. It is sad, but true, that there is little loyalty these days among outside consultants. They often take on far too may duties and treat conflicts of interest too lightly. I believe that the days of the SAB as an independent evaluating body of company science is numbered.

\section{Privacy versus publicity}

One much more serious issue around which the business and scientific cultures divide centers on the publication of research results. It is often clearly in the corporation's best interests that research findings be kept private far longer than would normally occur had these same findings been made in an aca- demic setting. Scientists, perhaps seeing life after a corporate existence, argue that they need publication priorities for their careers. The CEO argues that he needs silence for corporate competitiveness.

A somewhat uneasy truce has generally been accepted, in which publication immediately follows application for patent protection. As a scientist, I saw the dividing lines very clearly; as a CEO I am less comfortable. I live with it, not on grounds of business or logic, but because it is so important to the scientific staff, and I want to attract and to keep the best people I can.

\section{Dress code}

Not every nonscientist CEO is of the "white shirt, red tie" school, but most are perturbed by the absence of ties in the laboratory. This sometimes manifests itself in a "the bankers are coming" memo that politely requests ties and skirts on that day. The more subtle memo seeking the same end asks, "What time do people in the lab go for lunch?" One type of biotechnology company evolves from such CEOs is the "ties-are-for-managers" company. I know of no successful company that espouses this philosophy.

\section{Parking and other modes of travel}

Along with discussions on the dress code, nothing causes more lost work-time than discussions of who gets which parking space. The answer: No-one does.

There is nothing much one can do about personalized licenses plates-they are not paid for by the company after all-but I am not sure that the corporate culture is promoted by displaying the conversion of stock options on one's license plates: I have seen "144" and "RHu Cash." I think the more partisan "IL-4" and "InCy2" are cute, but who gets to use them?

The most sobering experience I have had with respect to a travel policy occurred a few years ago on a flight to Seattle. Secure in my first-class seat, I was greeted by a fellow board member Bill Gates-on his way to the coach section. When I sheepishly approached him later, he explained that he instituted the policy because it prevented endless discussions of who in the company got to travel in first class.

\section{Conclusions}

A bioentrepreneur's ability to marry the different perspectives of business and science into a culture that has a distinctive identity is essential to the success of the organization. Intrinsic to this undertaking is the effort to honor and respect the contributions of the company's disparate parts. Inspiring loyalty among employees based upon this culture is an important foundation for successful growth. 